\title{
DOES A LOW-SHRINK RESIN COMPOSITE INDUCE LESS STRESS AT THE ADHESIVE/DENTIN INTERFACE IN HIGH C-FACTOR CAVITIES?
}

\author{
Nadia M. Zaghloul*
}

\begin{abstract}
Objective: The aim of this in vitro study to compare $\mu$ TBS of two low shrink, TCD- based and dimer acid-based and one flowable SDR-based bulk-fill, resin composites; on the bottom of high C-factor cavities.

Materials \& methods: Thirty extracted noncarious human mandibular molars were used in the study. The occlusal enamel, in each tooth, was cut parallel to the occlusal surface, to expose a flat dentin surface. The cut teeth were randomly divided into two main groups $(n=15)$, depending on the preparation of dentin i.e., group I: high C-factor occlusal class I cavity, and group II: flat dentin surface at the same depth of the cavity floor. Single Bond Universal adhesive was used to bond the resin composites to dentin in the two groups. Teeth in each group were further subdivided into three subgroups $(n=5)$ according to the restorative materials used. In subgroup a: Surfil SDR flow, bulkfill flowable resin composite. In subgroup b, TCD-DI-HEA based, Charisma Topaz, nano-hybrid resin composite. In subgroup c, DDCDMA based, N'Durance, nano-hybrid resin composite. All the samples were subjected to 5000 cycle, thermocycling. Each specimen was sectioned longitudinally in both mesio-distal and bucco-lingual directions to obtain four beams per each sample. A total of 20 sticks were collected from each subgroup and subjected to $\mu$ TBS evaluation using universal testing machine and the results were then subjected to statistical analysis. The fractured surfaces were inspected under a stereomicroscope to determine the failure modes.
\end{abstract}

Results: The collected data were subjected to two way AOVA, followed by Tuky's post hoc test. Dentin preparation factor afforded insignificant higher $\mu$ TBS values with samples prepared in flat dentin surface compared to Samples with high C-factor class I cavities, when TCD- based, restorative material was used. DDCDMA based, ND, nanohybrid and SDR-based restorative material resulted in significant increase in the $\mu \mathrm{TBS}$ when applied to the flat dentin surfaces in comparison with the high $\mathrm{C}$-factor class I cavities. The three restorative materials were arranged in a descending order from TCD- based, DDCDMA based, followed by SDR resin, with no significant difference, when applied to the flat dentin surfaces. Yet, with high C-factor class I cavity restorations, $\mu$ TBS in SDR-based resin revealed the lowest significant values. Most of the failure modes are adhesive in nature.

* Assistant Professor, Department of Operative Dentistry, Faculty of Dentistry, Mansoura University 
Conclusions: Under the conditions of the present study, it might be concluded that TCD-based low-shrink resin composite investigated in this study perform well, in terms of compensation of polymerization shrinkage at the restoration/dentin interface and $\mu \mathrm{TBS}$ in high C-factor cavities. Conversely, the investigated Dimer acid-based and low-viscosity bulk-fill material based on SDR technology demonstrated unfavorable performance in high C-factor cavities.

KEYWORDS: Low shrink, SDR technology, resin composites, microtensile bond strength, C-factor.

\section{INTRODUCTION}

Polymerization shrinkage is a terrible problem, developed with the introduction of methacrylate based resin composite restoratives. During polymerization of resin monomers, the intermolecular van der Waals spaces in the monomers, are replaced by closer covalent bonds, resulted in volumetric shrinkage of the polymer mass. ${ }^{1}$ Although bonding to either enamel or dentin is greatly improved, the problem of adhesive failure still remains. ${ }^{2}$ The principal convincing reason of this situation is the polymerization shrinkage and its associated stresses developed at the restoration/ tooth structure interface. ${ }^{3}$ Several studies proved the direct relationship between these developed stresses and the restoration/tooth interface integrity, in terms of adaptation and bonding capacity. ${ }^{4-7}$ It is assumed that, if the polymerization shrinkage stresses exceed the bonding capacity at the restoration/ tooth interface, bonding failure will occur, with subsequent gap formation along the restoration/ tooth interface. ${ }^{8}$ In general, the volumetric shrinkage of most methacrylate based resin dental composites is ranged between 2 and $4 \%$ of the material volume. ${ }^{9}$ The magnitude of this shrinkage is dependent on material composition ${ }^{10}$, while the degree of developed polymerization stresses is a result of several factors including the configuration factor and the material composition. ${ }^{11,12}$ Numerous ways have been approved to reduce and compensate polymerization shrinkage and its developed stresses $^{13,14}$ including modification in the material composition. Two main strategies have been accomplished by the manufacturers to develop the low shrink resin composites, improved filler content ${ }^{15-18}$ and modified resin monomers.

Evolutions in the monomer composition have been introduced to overcome polymerization shrinkage. Initially, the low molecular weight monomers, like TEGDMA, were added to the high viscous Bis-GMA and UDMA monomer to optimize resin viscosity, allow proper filler loading and increase degree of conversion of the monomer mixture. Unfortunately, these diluents have increased reactive species per volume unite; led to increase in the polymerization shrinkage of the resin composite.${ }^{19}$ One strategy to compensate this problem is to partially or completely replace the low viscosity diluent monomers with a series of high molecular weight monomers. In this direction the low molecular weight TEGDMA is replaced by higher molecular weight monomers, such as ethoxylated BisGMA monomer, Bis-EMA, which is the Bis-GMA analogue with low viscosity. This lowered viscosity is gained through absence of hydroxyl groups in the monomer that produce hydrogen bonding. ${ }^{20}$ Another high molecular weight monomer is the hydrogenated dimer acid based dimethacrylates..$^{21-24}$ The high molecular-weight of this monomer with the decreased initial double-bond concentrations and low viscosity, motivate synthesis of this type of monomer to reduce polymerization contractions. Dimer acid is a derivative of an essential fatty acid, linoleic acid, comprises the main ingredient in many vegetable oils. Dimer acid methacrylates afforded decreased polymerization contraction, 
with increased degree of conversion. Added to that, the relatively low cross-linking density of this monomer could produce a high flexible polymer but with decreased elastic modulus. For the same reason, the high molecular weight methacrylic acid derived, tricyclodecane (TCD) urethane, monomer based resin composites were launched to dental markets. This low viscosity monomer has a rigid back bone, similar to that of Bis-GMA, that results in low shrinking behavior. ${ }^{14,22}$ The low viscosity of this monomer make it suitable to replace the diluents responsible for the high contraction of resins. In addition, high degree of conversion is achieved through the high reactivity of the acrylic acid ester containing urethane groups, in conjunction with the rigid structure of the TCD skeleton. ${ }^{23}$

A substantial development in the polymerization reaction dynamics is the incorporation of a photoactive group, photoinitiator, in a modified urethane-based methacrylate resin, to slow radical polymerization rate. This genuine lowered curing stresses is particularly exist in case of low filler loading. These patented resins are based on the stress decreasing resin, SDR, technology. It has been shown that this material resulted in great flexibility that allow dissipation of shrinkage stress..$^{24,25}$

Shrinkage stresses are induced when the polymerization shrinkage is restrained by the bond at the restoration/tooth interface, pulling the polymerized resin composite material apart of the cavity walls. ${ }^{26}$ The degree of stress development is influenced by the restored cavity shape and configuration, $\mathrm{C}$-factor. The $\mathrm{C}$-factor can be defined as the ratio between the bonded to the unbounded surface area of the restoration. ${ }^{27-29}$ It is evident that $\mathrm{C}$-factor negatively affects the restoration performance, including the microtensile bond strength..$^{27-31}$ The increased C-factor, associated with either class I or V cavities, increases the developed polymerization stresses at the restoration/tooth interface. These stresses are in competition with the bond strength of the polymerized materials, influence the partial or complete debonding of the restoration. As a rule, studies conducted to evaluate bond strengths to flat dentin surfaces, measure the adhesives or restorative systems performance. Several studies ${ }^{32-34}$ were conducted to investigate the influence of the restorative materials per se on the bonding characteristics, through evaluation of $\mu$ TBS in high C-factor cavities.

Through the previous introduction, distinct variations in the composition of resin phases of low-shrink resin composites available, so it is interesting to evaluate and compare the $\mu$ TBS of materials representing the different modifications previously mentioned, applied in a high C-factor cavities, under polymerization shrinkage stresses. The materials to be tested are three resin composites with high molecular weight monomers, Surfil SDR flow (SDR), Charisma Topaz (ChT) and N.Durance (ND). The null hypothesis was there is no difference in the microtensile bond strength of the low-shrink high molecular weight tested materials, bonded to flat dentin or high C-factor dentin cavity walls.

\section{MATERIALS AND METHODS}

The description of the selected materials under the main category of low-shrink resin composites, with one universal adhesive system are presented in table 1 . Thirty extracted human mandibular molars without any defects or restorations were collected from the Oral surgery department, Faculty of Dentistry, Mansoura University. Mesio-distal and bucco-lingual dimensions of the collected teeth were measured to ensure that all the teeth have almost similar dimensions. Teeth were collected due to periodontal problems. For disinfection, teeth were stored in a $0.5 \%$ chloramine-T solution for no more than 30 days. Before preparation, for ease of use, teeth were mounted, in acrylic resin (Acroston, under exclusive license of Acroston Dental CompanyCairo, Egypt), with the aid of Poly vinyl chloride rigid cylinders. 
TABLE (1) Restorative materials used

\begin{tabular}{|c|c|c|c|}
\hline Material & Filler loading & Composition & Manufacturer \\
\hline SureFil SDR flow & $\begin{array}{l}\text { Microhybrid } \\
68 \mathrm{wt} \% / 44 \mathrm{vol} \%\end{array}$ & $\begin{array}{l}\text { Resin: } \\
\text { UBPADMA, TEGDMA, Modified } \\
\text { UDMA } \\
\text { Filler: } \quad \text { Barium-alumino-fluoro-borosilicate } \\
\text { glass, Strontium alumino-fluoro-silicate glass }\end{array}$ & $\begin{array}{l}\text { Dentsply Caulk, } \\
\text { Milford, DE, USA }\end{array}$ \\
\hline Charisma Topaz & $\begin{array}{l}\text { Nanohybrid } \\
73 \mathrm{wt} \% / 58 \mathrm{vol} \%\end{array}$ & $\begin{array}{l}\text { Resin: TCD-DI-HEA, UDMA } \\
\text { Filler: Barium Aluminium Fluoride glass, pre- } \\
\text { polymerized fillers }\end{array}$ & $\begin{array}{l}\text { Heraeus Kulzer, Hanau, } \\
\text { Germany }\end{array}$ \\
\hline N.Durance & $\begin{array}{l}\mathrm{N} \text { a n o }-\mathrm{h} \text { y b r i d } \\
80 \mathrm{wt} \% / 65 \mathrm{vol} \%\end{array}$ & $\begin{array}{l}\text { Resin: DDCDMA, EBPADMA, UDMA } \\
\text { Filler:Ytterbium Fluoride, Barium Glass, Silica }\end{array}$ & Septodont, France \\
\hline $\begin{array}{l}\text { Single Bond Universal } \\
\text { Adhesive }\end{array}$ & & $\begin{array}{l}\text { MDP monomer, Dimethacrylate, HEMA, } \\
\text { ethanol, water, Vitrebond copolymer } \\
\text { (methacrylate modified polyalkenoic acid) }\end{array}$ & $\begin{array}{l}\text { 3M/ESPE, St Paul, MN, } \\
\text { USA }\end{array}$ \\
\hline
\end{tabular}

EBPADMA, Ethoxylated Bisphenol A dimethacrylate; TEGDMA, Triethyleneglycol dimethacrylate; TCD-DI-HEA, Bis-(acryloyloxymethyl) tricyclo $(5.2 .1 .02,6)$ decane; UDMA,urethane dimethacrylate; DDCDMA, Dimer Dicarbamate Dimethacrylate; EBPADMA,Ethoxylate Dimethacrylate; Bis-GMA, bisphenylglycidyl dimethacrylate; Bis-EMA, ethoxylated bisphenol-A dimethacrylate

\section{Teeth preparation}

The occlusal enamel, in each tooth, was cut parallel to the occlusal surface, using a diamond saw (Isomet4000, BuehlerLtd, LakeBluff, IL, USA) under water cooling, to remove the occlusal enamel and expose a flat surface of superficial dentin. The cut teeth were randomly divided into two main groups $(n=15)$, depending on the preparation of dentin i.e., group I: high C-factor occlusal class I cavity, and group II: flat dentin surface.

In group I, to be sure that the entire occlusal cavity was prepared completely in dentin, a permanent marker was used to border a square area, of $4 * 4 \mathrm{~mm}$, at the middle of the prepared flat dentin surface. A rectangular occlusal cavity was prepared in each tooth, using a \#560 high speed fissure carbide bur (MANI Inc, JAPAN), with air/water coolant, and the cavity floor was verified using \# 014 inverted cone diamond. The dimensions of the prepared cavity were $4 \pm 0.1 \mathrm{~mm}$ wide and $3.5 \pm 0.1 \mathrm{~mm}$ deep with a 4.5 C-factor. In group II, the occlusal flat dentin surface was further cut, using an Isomet, cervical to the first cut with $3.5 \pm 1 \mathrm{~mm}$, simulating the depth of the prepared cavity in group I. All the prepared dentin surfaces were washed with a copious water stream and dried before adhesive application.

\section{Application of the restorative systems}

Single Bond Universal adhesive was applied in a self-etch (SE) mode following the manufacturer's instructions. A thick layer of SE adhesive was applied to the dry and clean dentin surfaces in both groups, using a microbrush, with rubbing action for 20 seconds. The adhesive was then dried with compressed air for about 5 seconds, to ensure complete vaporization of the solvent, then light cured, with a LED curing unite (LEDition, IvoclarVivadent, Germany) at a light intensity of $800 \mathrm{~mW} / \mathrm{cm} 2$, for 10 seconds. Teeth in each group were further subdivided into three subgroups $(n=5)$ according to the restorative materials used. In subgroup a: Surfil SDR flow, bulk-fill flowable resin composite was inserted to fill the entire depth of the prepared cavity, in group I; while in group II a square metallic mold with the same dimensions 
of the prepared cavity in group I, $4 \pm 0.1 \mathrm{~mm}$ wide and $3.5 \pm 0.1 \mathrm{~mm}$ deep, was used to buildup resin composite above the flat dentin surface. All the applied resin composites were photo-cured for 20 seconds, using a LED curing unite at a light intensity of $800 \mathrm{~mW} / \mathrm{cm} 2$. In subgroup b, TCDDI-HEA based, Charisma Topaz, nanohybrid resin composite was applied, to either the prepared cavity or the metallic mold, in a horizontal incremental technique. Two increments were applied; with increment thickness not exceed $2 \mathrm{~mm}$. The increment thickness was verified using a graduated periodontal probe. Each increment was photocured, using a LED curing unite at light intensity of $800 \mathrm{~mW} / \mathrm{cm} 2$, for 20 seconds. In subgroup c, DDCDMA based, N'Durance, nano-hybrid resin composite was applied in the same manner discussed in subgroup b. After photo-curing, excess materials were removed with a diamond finishing stone (TR25EF, Mani, Japan) under air/water cooling, and then the samples were polished with Sof-lex XT polishing system (3M ESPE, St. Paul, MN, USA). All the samples in the two groups were then stored in distilled water, in an incubator, at $37 \pm 1 \mathrm{oC}$ for 24 hours. Samples were subjected to 5000 cycle, thermocycling (SD Mechatroniks thermocycler,
Germany), between $5-55^{\circ} \mathrm{C}$ with 20 seconds dwell time and 5 seconds transfer time.

\section{Microtensile bond strength test $(\mu \mathrm{TBS})$}

The center of each specimen, in the two groups, was sectioned longitudinally in both mesio-distal and bucco-lingual directions across the bonded interface of the cavity floor, along the long axis of the crown, with Isomet cutting machine and water coolant. Three parallel cuts were made in each direction to obtain four sticks of $0.9 \pm 1 \mathrm{~mm}^{2}$ crosssectional area. Each tooth was then horizontally cut at the cemento-enamel junction to obtain beams. A total of 20 beams were collected from each subgroup and subjected to $\mu$ TBS evaluation using universal testing machine (Instron, MA, USA). Each beam was attached to a custom made jig, utilized for mounting of beams into the universal testing machine using cyanoacrylate glue ((Zapit; DAVA, Corona, CA, USA) and then a tensile load was applied at a cross head speed of $0.5 \mathrm{~mm} / \mathrm{min}$, until the beam fractured. Bond strength was calculated in MegaPascal (BluehillLite software, Instron, $M A, U S A)$, and the results were then subjected to statistical analysis. Steps of specimen preparation in high $\mathrm{C}$-factor cavities are illustrated in figure 1.

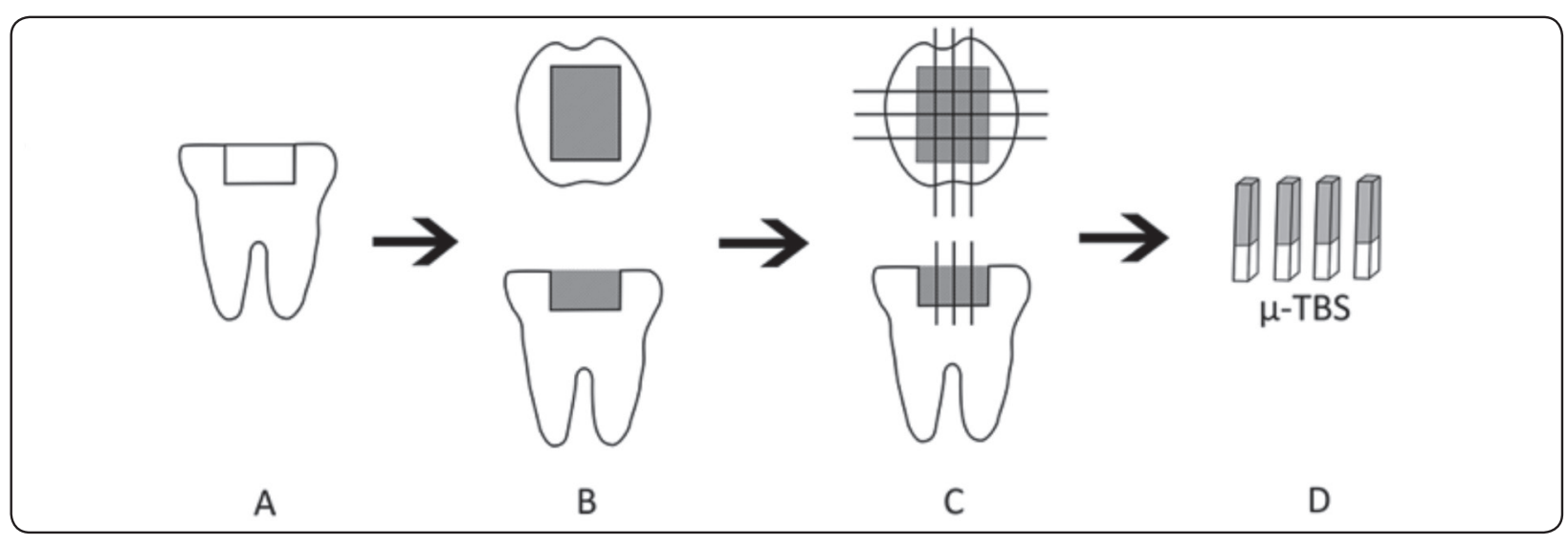

Figure 1: Schematic illustration of specimen preparation in high C-factor cavity. 


\section{Failure mode}

After fracture of the beams, the fractured surfaces were inspected under a stereomicroscope (Olympus, SZ61, Tokyo, Japan) at X40 magnification to determine the failure mode. The modes of failure were classified into, adhesive failure if the fractured surface was completely present at dentin/ restoration interface; cohesive failure if the fracture is completely present in the resin composite or in dentin; or mixed failure if the failures is present with adhesive/cohesive modes.

\section{RESULTS}

\section{Microtensile bond strength results ( $\mu \mathrm{TBS})$}

The data were scaled using Microsoft excel software and analyzed using SPSS V.20.0. Two-way analysis of variance (ANOVA) indicated significant differences for dentin preparation and restorative materials factors $(\mathrm{p}<0.05)$, table 2 . The mean $\mu$ TBS values were subjected to Tuky's post hoc test and tabulated in table 3, to compare the differences between each two subgroups.

Dentin preparation factor afforded insignificant higher $\mu$ TBS values $(\mathrm{p}<0.05)$ with samples prepared in flat dentin surface compared to Samples with high C-factor class I cavities, when TCD-DI-HEA based, ChT, nanohybrid restorative material was used. However, DDCDMA based, ND, nanohybrid and SDR microhybrid restorative materials resulted in significant increase in the $\mu$ TBS $(\mathrm{p}<0.0001)$ when applied to the flat dentin surfaces in comparison with the high $\mathrm{C}$-factor class I cavities.

TABLE (2) Two-Way ANOVA test Results (Both factors significantly influenced the results)

\begin{tabular}{|l|r|r|r|r|r|}
\hline Source & Type III Sum of Squares & df & Mean Square & F & Sig. \\
\hline Corrected Model & $1099.686^{\mathrm{a}}$ & 5 & 219.937 & 130.242 & .000 \\
Intercept & 110039.943 & 1 & 110039.943 & 65163.194 & .000 \\
Dentine & 416.641 & 1 & 416.641 & 246.726 & .000 \\
Material & 610.683 & 2 & 305.341 & 180.816 & .000 \\
Dentine * Material & 72.362 & 2 & 36.181 & 21.426 & .000 \\
Error & 192.510 & 114 & 1.689 & & \\
Total & 111332.139 & 120 & & & \\
Corrected Total & 1292.196 & 119 & & & \\
\hline R Squared = .851 (Adjusted R Squared = .844) & & & \\
\hline
\end{tabular}

TABLE (3) Tukey post Hoc Multiple comparison test results of restorative materials and C-factor

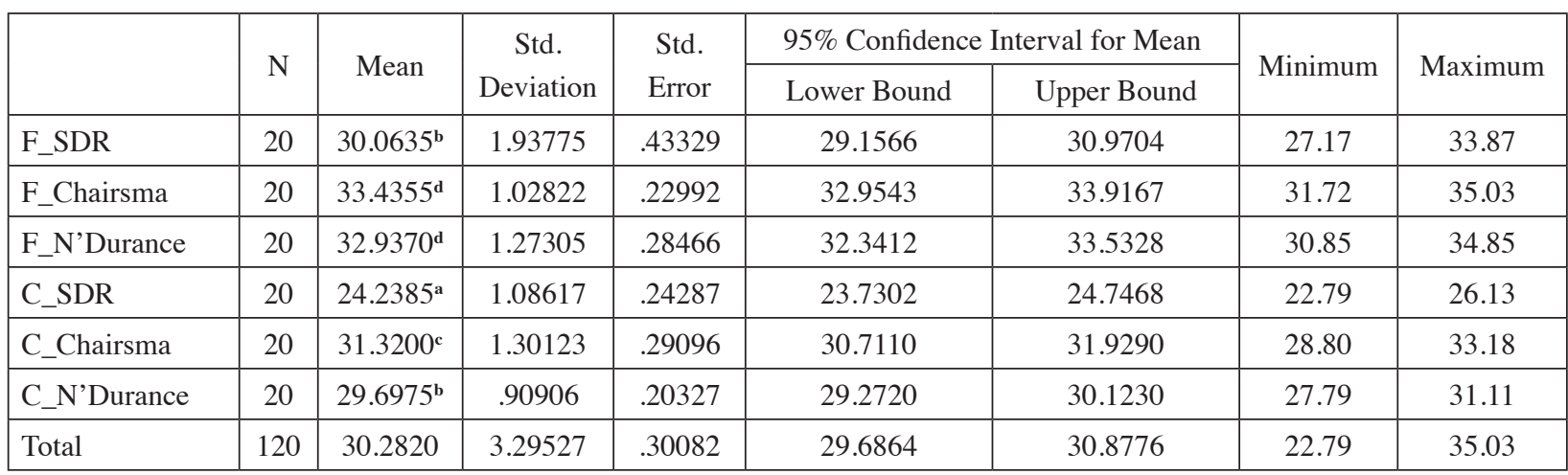

Each two dissimilar letters revealed a significant difference between groups. 
The three restorative materials were arranged in a descending order from TCD-DI-HEA based, ChT, resin composite (33.4355), DDCDMA based, ND, resin composite (32.9370) followed by SDR microhybrid resin (30.0635), with no significant difference, when applied to the flat dentin surfaces. Yet, with high C-factor class I cavity restorations, $\mu$ TBS in TCD-DI-HEA based, ChT, resin (31.3200) is significantly higher than in DDCDMA based, ND, resin (29.6975), while SDR revealed the lowest significant value (24.2385).

\section{Failure modes}

Failure mode distribution, adhesive, cohesive or mixed, for the two dentin preparations and resin composites were presented in table 4. The high C-factor class I cavity showed prominent adhesive failure, followed by mixed failure, cohesive failure in composite and cohesive failure in dentin. Flat dentin surface revealed mostly adhesive failure, to be followed by mixed failure, cohesive in dentin and cohesive in resin composite.

SDR resin composite, in high C-factor cavities, have the highest failure percentage in adhesive interface, to be followed by mixed and cohesive in resin composite, while with flat dentin surfaces failure modes were arranged in a descending order from adhesive, mixed and cohesive in either resin composite or cohesive in dentin. ChT resin composite, in high $\mathrm{C}$-factor cavities, have highest failure percentage in adhesive interface, to be followed by mixed and cohesive in resin composite, while with flat dentin surfaces failure modes were arranged in a descending order from adhesive, mixed and cohesive in resin composite. ND resin composite, in high $\mathrm{C}$-factor cavities and flat dentin surfaces, have highest failure percentage in adhesive interface, to be followed by mixed, and cohesive in either resin composite or dentin.

\section{DISCUSSION}

At present, evolutions in direct resin composites are focused on elimination or even minimizing the polymerization shrinkage of resin composites and associated stresses developed. Clinically, the polymerization shrinkage and its stresses can be compensated using several ways such as photocuring modes and equipments; and incremental techniques of resin composites application..$^{35}$ Actually, the perfect way to eliminate shrinkage and stresses is to use shrink-free resin composite. Yet, this hopeful material is not discovered. . $^{1,10-14}$ Because it is known that obtaining a high bond strength to dentin is competed with resultant Stresses from polymerization shrinkage of the restorative materials, hence low-shrink resin composite is the most important request at present..$^{36,37}$

Table (4) Persentage distribution of failure modes

\begin{tabular}{|l|l|l|l|l|l|}
\hline \multirow{3}{*}{ Dentin preparation } & \multirow{2}{*}{ Restorative materials } & \multicolumn{2}{|l|}{ Mode of failure } & \multicolumn{2}{l|}{} \\
\cline { 3 - 7 } & & Adhesive & Cohesive in dentin & Cohesive in composite & Mixed \\
\hline \multirow{4}{*}{ High C-factor } & Surfil SDR & 60 & - & 10 & 30 \\
\cline { 2 - 7 } & Charisma & 70 & - & 10 & 20 \\
\cline { 2 - 7 } & N'Durance & 60 & 10 & 10 & 20 \\
\hline \multirow{3}{*}{ Flat dentin } & Surfil SDR & 40 & 10 & 10 & 40 \\
\cline { 2 - 7 } & Charisma & 70 & 10 & - & 20 \\
\cline { 2 - 6 } & N'Durance & 60 & 10 & 10 & 20 \\
\hline
\end{tabular}


Microtensile bond strength of resin composites to dentin is the influence of several factors, involving the material composition, elastic modulus and polymerization contraction, ${ }^{38}$ in addition to the challenging effect of cavity $\mathrm{C}$-factor. ${ }^{26,29-33,37}$ In this study, the increase in the cavity $\mathrm{C}$-factor significantly decreases the values of $\mu \mathrm{TBS}$, when the bulk-fill SDR and N'Durance resin composites were used, while with Charisma Topaz resin composite, changing the cavity $\mathrm{C}$-factor insignificantly decrease the $\mu \mathrm{TBS}$ values. The calculated $\mathrm{C}$-factor for class I occlusal cavity and flat dentin surface, in the study, are 4.5 and 0.2 respectively. The keyword of these results is the flow relaxation of the polymerized resin. In the low $\mathrm{C}$-factor flat dentin, polymerized resin freely flows through the free unbounded five walls, with large surface area. When restoring a high $\mathrm{C}$-factor cavity, the opposite is true, where the resin is attached to five walls, with severely limited flow. If the developed polymerization stress exceed bond strength, resin/dentin interface

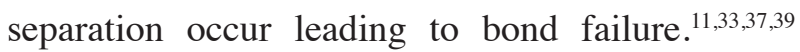
The results of the present study are in agreement with several studies ${ }^{32-34,40,41}$ in which the flat surface dentin preparation demonstrates no influence on polymerization stress propagation and $\mu \mathrm{TBS}$ of resin composites to dentin, while the increase in the $\mathrm{C}$-factor adversely affects $\mu \mathrm{TBS}$ values, in relation to the materials polymerization contraction values. Failure modes are mostly adhesive in nature indicating that polymerization contraction does exceed the restoration/dentin adhesive interface. The null hypothesis was rejected, as increased C-factor significantly impair bonding to dentin when Dimer acid-based and SDR based resin composites were used, while the TCD-based material sill have, although insignificant, effect on bonding capacity in high $\mathrm{C}$-factor cavities. In addition TCD-based resin composite showed the significant highest bond strength, with Dimer-based resin composite is significantly higher bond strength than SDR- based one.
In the present study Bis-GMA monomer is completely substituted with UDMA formulations, in the three tested materials, with a variety of added other monomers. The low viscosity formulations of urethane dimethacrylate (UDMA) became widely common for dental resin composites, to overcome limitations of Bis-GMA and the diluents TEGDMA. The low viscous, flexible UDMA copolymers generally donate higher flexural strength, elastic modulus and hardness, than Bis-GMA, with higher monomer to polymer comversion. ${ }^{42-44}$

The nanohybrid resin composite Charisma Topaz revealed the highest $\mu$ TBS values, regaredless the dentin preparations, which are significant in comparison with SDR based resin composite, but significant in comparison with N'Durance in high C-factor only. This result confirms that ChT posses a detectable low-shrink property that could compensate stresses at the restoration/resin interface. The corner stone for the superior results obtained with Charisma Topz nanohybrid resin composite is the resin matrix composition. The nanohybrid Charisma resin composite is composed of a unique high molecular weight Bis-(acryloyloxymethyl) tricyclo (5.2.1.02,6) decane (TCD-DI-HEA) monomer, with a rigid backbone (tricyclodecane). Regardless the degree of high $\mathrm{c}=\mathrm{c}$ conversion, the decreased monomer vibration allows closer distance between the unpolymerized monomers, with high packing density. During polymerization, small changes in the cross-linking monomers distance, reduces polymerization shrinkage. ${ }^{14,45-47}$ Added to that, it posses low viscosity, enough to replace low molecular weight diluents in resin composites, with high reactivity of the acrylic acid esters. ${ }^{14,22,23}$ Marchesi et al. ${ }^{14}$ and de Oliveira et $\mathrm{a}^{48}$ reported that TCD-DI-HEA containing resin composites induced significantly reduced polymerization stresses.

Next to Charisma Topaz, a singular nanohybrid resin composite with dimer acid based methacrylate, N'Durance, confer slightly lower but comparable 
$\mu$ TBS values in flat dentin surfaces, and significant lower $\mu$ TBS in high C-factor. The composition of the resin matrix is, Dimer Dicarbamate Dimethacrylate (DDCDMA), Ethoxylate Dimethacrylate (EBPADMA) and UDMA. The high molecular weight dimer acid-based monomer was developed in an attempt to reduce volumetric shrinkage during polymerization with decreased initial doublebond concentrations. The hydrogenated dimer acid derived monomer contains a core structure with an aromatic moiety, urethane groups, and two side arms. Reduced polymerization shrinkage, shrinkage stress and high degree of conversion were observed for dimer acid homopolymers. ${ }^{21-24}$ In addition, high flexibility but low elastic modulus of the polymerized material is the profit of low cross-link density of the low viscosity dimer acid dimethacrylates. When comparing N'Durance with a nanohybrid resin composite containing TCDDI-HEA (Venus Diamond), N’Durance possesses unnoticeable inferior properties in terms of flexural strength, modulus of elasticity values, with shrinkage and shrinkage stress values ${ }^{45,46,49,50}$, that could produce higher stress at the cavity walls in high C-factor cavities.

Another high molecular weight monomer incorporated in N'Durance resin matrix is Ethoxylatedbisphenol A dimethacrylate (BisEMA). This monomer is a Bis-GMA analogue with higher molecular weight but without the strong secondary molecular interactions given by hydroxyl groups, which reduces its viscosity and allows for higher DC and better mechanical properties to be achieved. Lower viscosity of BisEMA may be attributed to the absence of hydrogen bonding due to the lack of hydroxyl groups..$^{20}$ This high molecular weight monomer is used mainly to completely or partially replace the low molecular weight diluent monomers, such as TEGDMA. Combination of BisEMA with conventional monomers such as UDMA or Bis-GMA, has been found to provide lowered polymerization shrinkage. ${ }^{51}$
Flat dentin surface revealed lowest, although insignificant, $\mu$ TBS values when Surfil SDR flow resin composite was tested. Neverthless, the high C-factor cavities resulted in significant impairment in the $\mu$ TBS when restored with this material. This is an indication that Surfil SDR flow develops high polymerization shrinkage with high stress. In Surfil SDR flow resin matrix, the traditionally used Bis-GMA is totally replaced by modified urethane dimethacrylate (UDMA) and Ethoxylate Dimethacrylate (EBPADMA). In addition, triethylene glycol dimethacrylate (TEGDMA) is added as a diluent. TEGDMA is a flexible low viscous monomer that allows higher incorporation of inorganic fillers and improves handling characteristics.Unfortunately, addition of TEGDMA impairs the physical and mechanical properties of the final product. ${ }^{52-55}$ Although TEGDMA flexibility donates the increased degree of conversion, the higher number of reactive species per volume unit contributes to increase in polymerization shrinkage of its respective composite. ${ }^{19,51}$ Incorporation of TEGDMA in SDR may be the explanation of inferior $\mu \mathrm{TBS}$ obtained with this material in the two test groups. The significant decrease in the $\mu \mathrm{TBS}$ in class $\mathrm{I}$, high $\mathrm{C}$-factor maximizes the role of polymerization contraction and the developed stress at the adhesive/dentin interface. ${ }^{37,39}$

Although the modified UDMA monomer, incorporated photoactive polymerization modulator, regulates the polymerization stress of the Surfil SDR flow resin phase, through the SDR technology 25 , without reduction of the polymerization rate ${ }^{56}$; the filler content was remarkably reduced, $68 \mathrm{wt} \%$ and $44 \mathrm{vol} \%$. Filler loading in Surfil SDR flow is reduced in an attempt to increase translucency and depth of cure..$^{57-59}$ There is an inverse linear relationship between the filler loading and polymerization shrinkage, where the lower filler content increases the amount of resin phase. The increased resin content in the composite increases the reactive site per unit volume, with increased polymerization shrinkage and decreased mechanical properties. ${ }^{60-63}$ 
Benetti et al., ${ }^{62}$ demonstrated that the low-viscosity bulk-fill resin composites produced a significantly higher depth of cure but a significant higher polymerization contraction.

Most of researches to study the impact of polymerization contraction and polymerization stress have been reported directly through mechanical testing ${ }^{64}$ or indirectly through measurements of cuspal deflection ${ }^{65}$, microleakage assessments. ${ }^{66} \mathrm{In}$ the present study, polymerization contraction stress was indirectly assessed through the $\mu$ TBS measurements in a high $\mathrm{C}$-factor class I cavity. The results of this study might confirm expectations arise from previous researchs ${ }^{45-50}$ suggested low-shrink resin composites as hopeful esthetic restorative alternatives. However, long-term clinical investigations of low-shrink resin composites still required before recognition of validity of these materials.

\section{CONCLUSIONS}

Under the conditions of the present study, it might be concluded that $\mu \mathrm{TBS}$ is a material and configuration factor dependent. TCD-based low-shrink resin composite investigated in this study perform well, in terms of compensation of polymerization shrinkage at the restoration/dentin interface and $\mu \mathrm{TBS}$ in high $\mathrm{C}$-factor cavities. Conversely, the investigated Dimer acid-based and low-viscosity bulk-fill material based on SDR technology demonstrated unfavorable performance in high C-factor cavities.

\section{REFERENCES}

1. Braga RR, Ballester RY, Ferracane JL. Factors involved in the development of polymerization shrinkage stress in resin-composites: a systematic review. Dent Mater. 2005;21:962-70.

2. Hilton TJ. Can modern restorative procedures and materials reliably seal cavities? In vitro investigations. Part 1. Am J Dent. 2002;15:198-210.

3. Bowen RL, Nemoto K, Rapson JE. Adhesive bonding of various materials to hard tooth tissues: forces developing in composite-materials during hardening. J Am Dent Assoc1983;106:475-7.
4. Gonc, alves F, Pfeifer CS, Ferracane JL, Braga RR. Contraction stress determinants in dimethacrylate composites. J DentRes 2008;87:367-71.

5. Braga RR, Ferracane JL, Condon JR. Polymerization contraction stress in dual-cure cements and its effect oninterfacial integrity of bonded inlays. J Dent 2002;30:333-40.

6. Civelek A, Ersoy M, L'Hotelier E, Soyman M, Say EC. Polymerization shrinkage and microleakage in Class II cavities of various resin composites. Oper Dent. 2003; 28:635-41

7. Ilie N, Kunzelmann K, Hickel R. Evaluation of microtensile bond strengths of composite materials in comparison to their polymerization shrinkage. Dent Mater. 2006;22:593-601.

8. Ferracane JL, Hilton TJ. Polymerization stress-is it clinically meaningful? Dent Mater. 2016;32:1-10.

9. Kleverlaan CJ, Feilzer AJ. Polymerization shrinkage and contraction stress of dental resin composites. Dent Mater. 2005;21:1150-7.

10. Stansbury JW, Trujillo-Lemon M, Lu H, Ding X, Lin Y, Ge J.Conversion-dependent shrinkage stress and strain in dental resins and composites. Dent Mater 2005;21:56-67.

11. .Feilzer AJ, De Gee AJ, Davidson CL. Quantitative determination of stress reduction by flow in composite restorations. Dent Mater 1990;6:167-71.

12. Venhoven BAM, de Gee AJ, Davidson CL. Polymerization contraction and conversion of light-curing BisGMA-based methacrylate resins. Biomaterials 1993;14:871-5.

13. Watts DC, Schneider LFJ, Marghalani HY. Bond-disruptive stresses generated by resin composite polymerization in dental cavities. J Adhes Sci Technol 2009;23:1023-42.

14. Marchesi G, Breschi L, Antoniolli F, Di Lenarda R, Ferracane J,Cadenaro $\mathrm{M}$. Contraction stress of low-shrinkage compositematerials assessed with different testing systems. DentMater 2010;26:947-53.

15. Craig RG, Powers JM. Restorative dental materials. 11th ed.St. Louis: Mosby; 2002.

16. Mitra SB, Wu D, Holmes BN. An application of nanotechnology in advanced dental materials. J Am Dent Assoc 2003;134:1382-90.

17. Kleverlaan CJ, Feilzer AJ. Polymerization shrinkage andcontraction stress of dental resin composites. Dent Mater2005;21:1150-7. 
18. Chen MH, Chen CR, Hsu SH, Sun SP, Su WF. Low shrinkagelight curable nanocomposite for dental restorative material. Dent Mater 2006;22:138-45.

19. Peutzfeldt A. Resin composites in dentistry: the monomer systems. Eur J Oral Sci. 1997;105:97-116.

20. Ogliari FA, Ely C, Zanchi CH, Fortes CB, Samuel SM, Demarco FF, et al.. Influence of chain extender length of aromatic dimethacrylates on polymer network development. Dent Mater 2008;24:165-71.

21. Trujillo-Lemon M, Ge J, Lu H, Tanaka J, Stansbury J. Dimethacrylate derivates of dimer acid. J Polymer Science 2006;44:3921-9.

22. Ferracane JL. Resin composite - state of the art. Dent Mater. 2011;27:29-38.

23. Kurokawa R, Finger WJ, Hoffmann M, et al. Interactions of self etch adhesives with resin composites. J Dent 2007;35:923-9.

24. Roggendorf MJ, Krämer N, Appelt A, Naumann M, Frankenberger R. Marginal quality of flowable 4-mm base vs. conventionally layered resin composite. J Dent. 2011;39:643-7.

25. Ilie N, Hickel R. Investigations on a methacrylate-basedflowable composite based on the SDR (TM) technology. Dent Mater. 2011;27:348-55.

26. Alomari QD, Omar R, Akpata SE. Effect of LED curing modes on postoperative sensitivity after class II resin composite restorations. J Adhes Dent. 2007;9:477-81.

27. Braga RR, Boaro LC, Kuroe T, Azevedo CL, Singer JM. Influence of cavity dimensions and their derivatives (volume and ' $\mathrm{C}$ ' factor) on shrinkage stress development and microleak-age of composite restorations. Dent Mater. 2006;22:818-23.

28. Pfeifer CS, Braga RR, Cardoso PE. Influence of cavity dimensions, insertion technique and adhesive system on microleakage of Class V restorations. J Am Dent Assoc. 2006;137:197-202.

29. Duarte S, Jr, Dinelli W, da Silva MH. Influence of resin composite insertion technique in preparations with a high C-factor. Quintessence Int. 2007;38:829-35.

30. Nikolaenko SA, Lohbauer U, Roggendorf M, Petschelt A, Dasch W, Frankenberger R. Influence of c-factor and layering technique on microtensile bond strength to dentin. Dent Mater. 2004;20:579-85.

31. Cunha LG, Alonso RC, Neves AC, de Goes MF, Ferracane JL, Sinhoreti MA. Degree of conversion and con- traction stress development of a resin composite irradiated using halogen and LED at two C-factor levels. Oper Dent. 2009;34:24-31.

32. Van Ende A, Mine A, De Munck J, Poitevin A, Van Meerbeek B. Bonding of low-shrinking composites in high Cfactor cavities. J Dent. 2012;40:295-303.

33. El-Sahn NA, El-Kassas DW, El-Damanhoury HM, Fahmy OM, Gomaa H, Platt JA. Effect of C-factor on Microtensile Bond Strengths of Low-Shrinkage Composites. Operative Dentistry. 2011; 36: 281-92.

34. Taneja S, Kumar P, Kumar A. Comparative evaluation of the microtensile bond strength of bulk fill and low shrinkage composite for different depths of Class II cavities with the cervical margin in cementum: An in vitro study. 2016;19:532-5.

35. Ferracane JL. Developing a more complete understanding of stresses produced in dental composites during polymerization. Dent Mater. 2005;21:36-42.

36. Bouillaguet S, Troesch S, Wataha JC, Krejci I, Meyer J, Pashley DH. Microtensile bond strength between adhesive cements and root canal dentin. Dent Mater. 2003;19:119205.

37. Nikolaenko SA, Lohbauer U, Roggendorf M, Petschelt A, Dasch W, Frankenberger R. Influence of c-factor and layering technique on microtensile bond strength to dentin. Dent Mater.2004;20:579-85.

38. Goracci C, Margvelashvili M, Apicella D, Sedda M, Magni E, Ferrari M. Influence of resin composite mechanical properties on adhesive microtensile bond strength to dentin. J Adhes Dent. 2011;13:323-31.

39. Feilzer AJ, De Gee AJ, Davidson CL. Setting Stress in Composite Resin in Relation to configuration of the Restoration. J DENT RES. 1987;66:1636-9.

40. Van Ende A, De Munck J, Van Landuyt K, Van Meerbeek B. Effect of Bulk-filling on the Bonding Efficacy in Occlusal Class I Cavities. J Adhes Dent. 2016;18:119-24.

41. Braga SSL, OliveiraLRS, Rodrigues RB, Bicalho AA, VR Novais VR, Armstrong S, Soares CJ. The Effects of Cavity Preparation and Composite Resin on Bond Strength and Stress Distribution Using the Microtensile Bond Test. Oper Dent.2018;43: 81-9.

42. Tanimoto Y, Hayakawa T, Nemoto K. Analysis of photopolymerization behavior of UDMA/TEGDMA resin mixture and its composite by differential scanning calorimetry. J Biomed Mater Res B Appl Biomater 2005;72:310-15. 
43. Floyd CJ, Dickens SH. Network structure of Bis-GMA- and UDMA-based resin systems. Dent Mater 2006;22:1143-9.

44. Goncalves F, Pfeifer CC, Stansbury JW, Newman SM, Braga RR. Influence of matrix composition on polymerization stress development of experimental composites. Dent Mater 2010; 26:697-703.

45. Yamasaki LC, De Vito Moraes AG, Barros M, Lewis S, Francci C, Stansbury JW, et al. Polymerization development of "low-shrink" resin composites: reac-tion kinetics, polymerization stress and quality of network. Dent Mater. 2013;29:e169-79.

46. Boaro LC, Gonçalves F, Guimarães TC, Ferracane JL, Pfeifer CS, Braga RR. Sorption, solubility, shrinkage and mechanical properties of "low-shrinkage" commercial resin composites. Dent Mater.2013;29:398-404.

47. Roy KK, Kumar KP, John G, Sooraparaju SG, Nujella SK, Sowmya K. A comparative evaluation of effect of modern-curing lights and curing modes on conventional and novel-resin monomers.J Conserv Dent.2018;21:68-73.

48. de Oliveira DCRS, Rovaris K, Hass V, Souza-Júnior EJ, Haiter-Neto F, Sinhoreti MAC. Effect of Low Shrinkage Monomers on Physicochemical Properties of Dental Resin Composites. Braz. Dent. J.2015;26: Print version ISSN 0103-6440

49. Lui H, Trujillo-Lemon M, Ge J, Stansbury JW. Dental resins based on dimer acid dimethacrylates: a route to high conversion with low polymerization shrinkage. Compendium of continuing education in dentistry 2010;31:1-4.

50. Bracho-Troconis C, Trujillo-Lemon M, Boulden J, Wong N, Wall K, Esquibel K. Characterization of N'Durance: a nanohybrid composite based on new nano-dimer technology. Compendium Cont Ed Dent 2010;31:5-9.

51. Obici AC, Sinhoreti MAC, De Goes MF, Consani S, Sobrinho LC. Effect of the photo-activation method on polymerizationshrinkage of restorative composites. Oper Dent2002;27:192-8.

52. Peutzfeldt A. Resin composites in dentistry: the monomer systems. Eur J Oral Sci 1997;105:97-116.

53. Sideridou ID, Karabela MM, Bikiaris DN. Aging studies of light cured dimethacrylate-based dental resins and a resin composite in water or ethanol/water. Dent Mater 2007;23:1142-9.

54. Janda R, Roulet JF, Latta M, Ruttermann S. Water sorption and solubility of contemporary resin-based filling materials. J Biomed Mater Res B Appl Biomater2007;82:545-51.
55. Lempel E, Czibulya Z, Kovács B, Szalma J, Tóth Á, Kunsági-Máté S, Varga Z, Böddi K. Degree of Conversion and BisGMA, TEGDMA, UDMA Elution from Flowable Bulk Fill Composites. Int J Mol Sci. 2016;17: e732-44.

56. Nedeljkovic I, Teughels W, De Munck J, Van Meerbeek B, Van Landuyt KL. Is secondary caries with composites a material-based problem? Dent Mater. 2015;21: e247-77.

57. Van Ende A, De Munck J, Van Landuyt KL, Poitevin A, Peumans M, Van Meerbeek B. Bulk-filling of high C-factor posterior cavities: effect on adhesion to cavity-bottom dentin. Dent Mater 2013;29:269-77. 16.

58. Flury S, Hayoz S, Peutzfeldt A, Husler J, Lussi A. Depth of cure of resin composites: is the ISO 4049 method suitable for bulk fill materials? Dent Mater 2012;28:521-8.

59. Lee YK. Influence of filler on the difference between the transmitted and reflected colors of experimental resin composites. Dent Mater. 2008; 24:1243-7.

60. Kleverlaan CJ, Feilzer AJ. Polymerization shrinkage and contraction stress of dental resin composites. Dent Mater. 2005;21:1150-7.

61. Leprince JG, Palin WM, Vanacker J, Sabbagh J, Devaux J, Leloup G. Physicomechanical characteristics of commercially available bulk-fill composites. J Dent 2014;42:9931000 .

62. Benetti AR, Havndrup-Pedersen C, Honoré D, Pedersen MK, Pallese U. Bulk-Fill Resin Composites: Polymerization Contraction, Depth of Cure, and Gap Formation. Oper Dent. 2015;40:190-200.

63. Wang Z, Chiang MY. System compliance dictates the effect of composite filler content on polymerization shrinkage stress. Dent Mater. 2016;32:551-60.

64. Tobias T. Tauböck, Franziska Jäger, Thomas Attin. Polymerization shrinkage and shrinkage force kinetics of high- and low-viscosity dimethacrylate- and ormocerbased bulk-fill resin composites. Odontol. 2018;20:1-8.

65. Enochs T, E.Hill AE, Worley CE, Veríssimo C, Tantbirojn D, Versluis A.Cuspal flexure of composite-restored typodont teeth and correlation with polymerization shrinkage values. Dent Mater. 2018;34:152-60.

66. Politi I, McHugh LEJ, Al-Fodeh RS, Fleming GJP. Modification of the restoration protocol for resin-based composite (RBC) restoratives (conventional and bulk fill) on cuspal movement and microleakage score in molar teeth. Dent Mater. 2018;34:1271-7. 